\title{
Study on Silicification Information Extraction Technology Based on ASTER Thermal Infrared Data
}

\author{
Junhu WANG \\ Beijing Research Institute of Uranium Geology, National \\ Key Laboratory of Remote Sensing Information and Image \\ Analysis Technology \\ Beijing, China \\ tcwjh2001@163.com
}

\begin{abstract}
On the basis of analyzing thermal infrared technology application potential on the uranium prospecting, the paper applies this technology to the silicification information extraction. Taking TAOSHAN granite-type uranium deposits in south china for example, the paper established a new set of technology method in the silicification information extraction for hydrothermal uranium deposits based on the ASTER thermal infrared data. Futhermore, the result conformed to the geological facts and they were validated in the field. Above all, the practice proves that this method breakthroughs the bottleneck that it is difficult to extract the silicification information by visibleshortwave infrared remote sensing technology. what's more, it will play an active role in the uranium prospecting.
\end{abstract}

Index Terms-Silicification, extraction,ASTER, thermal infrared

\section{INTRODUCTION}

With the growing global demand for energy, the aggravation of greenhouse effect and climate change, nuclear energy as a kind of clean, economic and safe energy, is much more to get attention of the world. Therefore, it is more important to carry out the efficient technology research of uranium resources exploration and increase the reserves of uranium resources. Nowadays, the exploration of uranium resource has become more difficult, recently. Based on the new metallogenetic concept, the research of uranium exploration based on the new technology of remote sensing becomes the research focus ${ }^{[1]}$. Since the sensor of ASTER was launched, it provides the low-cost multi-spectral thermal infrared data. It can distinguish the important rocks and minerals that can't be discerned by visible-short wave data. And hence, the technology of thermal infrared remote sensing will play an important role in the resource prospecting.

Silicification is one type of the widely development mineralization alteration in the granite-type uranium deposits. It is the secondary quartz or quartz recrystallization generated in the surrounding rock during hydrothermal alteration. The silicified zone is the fault zone filling with quartz veins or connected with siliceous tectonite (cataclasite, breccia, mylonite rock) in both ends of the trend. If the large silicified zone, quartz veins or alteration zones go through the granite body, it indicates that there was intense hydrothermal activity in the fault zone ${ }^{[2]}$.Therefore, silicification information such as quartz veins, siliceous veins and silicified zone is an important clue in the granite-type uranium prospecting.

\author{
Jielin ZHANG \\ Beijing Research Institute of Uranium Geology, National \\ Key Laboratory of Remote Sensing Information and Image \\ Analysis Technology \\ Beijing, China
}

Based on the background mentioned above, the paper took the TAOSHAN granite-type uranium deposits in south china for example, carried out the research of silicification information extraction technology based on the ASTER thermal infrared data. As a result, the paper identified the silicified fault zone closely associated with uranium mineralization and found a good uranium mineralization point. All of work could provide a useful reference for uranium deposits prospecting.

\section{GeOlOGiCAl SETTING OF THE STUDY AREA}

The TAOSHAN uranium deposits are located in northern end of TAOSHAN-ZHUGUANG uranium mineralization zone. It has experienced multiple stages of tectono-magmatic activity, The granite exposed is a kind of composite body which formed in multi-stage. Sinian metamorphic rocks locate in the outside of research area. The red late cretaceous clastic rocks are in the local distribution. The major granite bodies were formed in the triassic-early cretaceous, and the scale of magmatism was large. Two kinds of structures were mostly developed in this area and the strike is NNE and NE. They have experienced a long-term and multi-stage activities, and played a vital role in the magmatic activity and uranium mineralization in the region. The wall rock alteration was more developed in the study area, and alteration type of all kinds of mineralization is similar. They are chloritization, sericitization, silicification, kaolinization, hematitization,fluoritization and so on ${ }^{[3]}$.

\section{ASTER THERMAL INFRARED (TIR) DATA PRE_ROCESSING}

\section{A. The radiometric calibration of ASTER TIR data}

The product-level of ASTER data is 1B grade level, the data of this level has been made geometric correction and radiometric correction on the $1 \mathrm{~A}-\mathrm{level}$ data. Whereas, the data of image is still DN value, and there is a good linearity between DN value and spectral radiance. And hence, DN value needs to be changed into spectral radiance before extracting the information by thermal infrared data. The paper corrected the value of image into spectral radiance according to the gain and offset of each ASTER TIR band ${ }^{[4]}$, the formula is as follows: 
Radiance $=\mathrm{Gain} * \mathrm{DN}+$ offset

\section{B. Atmospheric calibration of ASTER TIR data}

Atmospheric effects in general can't be ignored in the radiation temperature and features emissivity measurement. It makes thermal infrared signal distort which is recorded by sensor. As a result, remote sensing information deviates from the ground truth. Therefore, the signal received by thermal infrared sensor consists of two parts. One part of radiation is its thermal radiation emitted by measured objects, another part is emitted from surrounding environment. Two parts are mixed as the apparent temperature ${ }^{[5]}$.To inverse the surface temperature and emissivity accurately, apparent radiance temperature is not enough, further atmospheric correction must be made to remove the atmospheric effects.

The paper adopted the In-Scene Atmospheric Compensation Algorithms (ISAC), because atmospheric parameters synchronizing with ASTER TIR data are not readily available, and the emissivity data only requires higher relative value rather than absolute value. This algorithm assumes that the atmosphere above data source is homogeneous, and surface objects are blackbody without downlink radiation. Atmospheric uplink radiation and atmospheric transmission could be approximately calculated in accordance with the following method: First of all, the surface temperature of each pixel is estimated from data, then the brightness temperature is estimated by the Planck formula assuming emissivity is equal to one. Futhermore, the scatter diagram of radiation rate and the brightness temperature are drawn using one of two methods above in order to determine a curve. As a result, atmospheric uplink radiation could be calculated from the tilt and offset of curve ${ }^{[6]}$. Based on the above principle, the paper completed the atmospheric correction by IDL programming language.

\section{SILICIFICATION ALTERATION INFORMATION EXTRACTION BASED ON ASTER THERMAL INFRARED DATA}

\section{A. The emissivity spectral characteristics of silicified altered rocks}

The major mineral composition is quartz in the silicified altered rocks, and the content of $\mathrm{SiO}_{2}$ is more than $85 \%$, some is more than $95 \%$ in the rocks. Therefore, the spectral characteristics of silicified altered rock is mainly generated by vibration of $\mathrm{Si}-\mathrm{O}$ bond of quartz. However, $\mathrm{Si}-\mathrm{O}$ bond in the visible, near infrared and short-wave infrared region does not have absorption feature, but there is residual radiation feature (low emissivity )in the thermal infrared bands according to the emissivity spectral library of ASTER(Fig1,Fig2). The quartz in the rocks can be extracted according to the center wavelength of the residual radiation bands, so as to achieve the purpose of silicification information recognition.

It shows the emissivity spectra of microcrystalline quartz and coarse quartz measured in the laboratory in figure 1 and figure 2. As can be seen from Fig 1 and Fig2, the center wavelength and the emissivity value of the residual radiation bands for quartz with different particle size are different. There is a strong sharp residual radiation band at $8.16 \mu \mathrm{m}$ and a weak residual radiation band at $8.47 \mu \mathrm{m}$ for the microcrystalline quartz in Fig1, besides, there are three a little strong residual radiation bands between 8.9 to $9.3 \mu \mathrm{m}, 10.9$ to $11.42 \mu \mathrm{m}$ and $13.78 \mu \mathrm{m}$, and there are two narrow and weak residual radiation band at $12.5 \mu \mathrm{m}$ and $12.7 \mu \mathrm{m}$. In a word, the diagnostic wavelength center of residual radiation bands of microcrystalline quartz locates at $8.16 \mu \mathrm{m}, 9.1 \mu \mathrm{m}, 11 \mu \mathrm{m}$ and $13.78 \mu \mathrm{m}$ nearby. In addition, the whole emissivity value of microcrystalline quartz is generally high, it is above 0.96 , and there are small changes in its value. Judging from Fig2, there are two strong residual radiation band for coarse quartz at $8.48 \mu \mathrm{m}$ and $8.8-9.0 \mu \mathrm{m}$. There are two low and weak residual radiation band at $12.5 \mu \mathrm{m}$ and $12.7 \mu \mathrm{m}$.Above all, the diagnostic wavelength center of residual radiation band of coarse quartz locates at $8.48 \mu \mathrm{m}, 9.0 \mu \mathrm{m}$ nearby, and the emissivity of coarse quartz changes with the wavelength value, it is between 0.2-1.0, it may be because there are more impurities in the rock samples so as to weaken the emissivity of quartz.

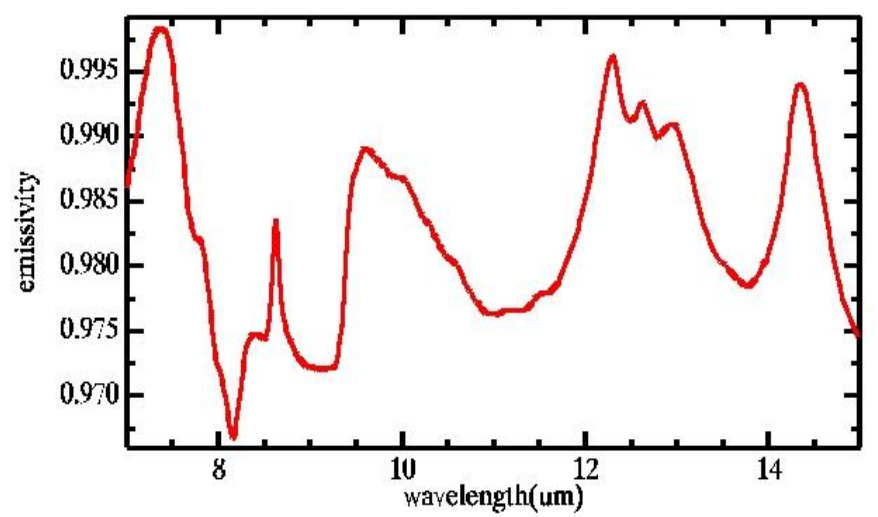

Fig.1. Thermal infrared emissivity spectral graph of microcrystalline quartz (From ASTER Library)

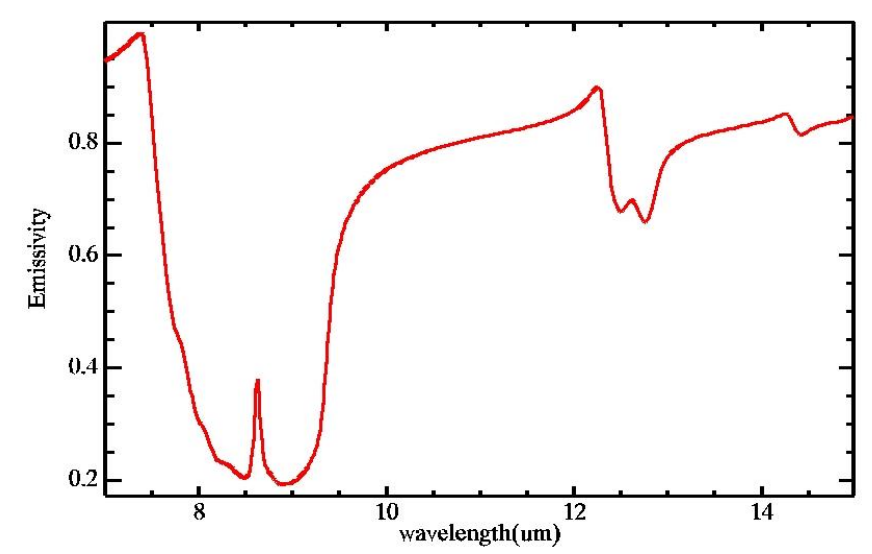

Fig.2. Thermal infrared emissivity spectral graph of coarse quartz (From ASTER Library)

There are five spectral bands of ASTER thermal infrared (TIR) data , their spatial resolution of pixel is 90 meters. And hence, there is more advantage than MODIS and AVHRR data. Compared with thermal infrared data of ETM6,the spatial resolution of ASTER data is lower, However, its higher spectral resolution makes thermal infrared data of ASTER has a good ability to extract the silicification information, and it 
has achieved good results in practical applications. The paper carried out the field emissivity measurement of rock samples made of coarse quartz mostly in the silicified zone. According to the features of ASTER thermal infrared data, the measured emissivity spectral curves were resampled to match with the spectral resolution of ASTER data, in order to lay the foundation to extract the silicification alteration information by ASTER thermal infrared data. The resampled curve is shown in Figure 3.

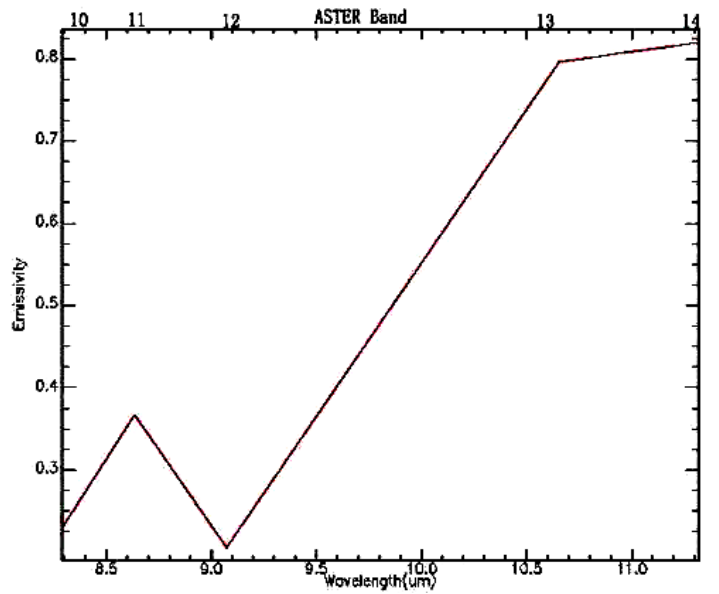

Fig.3.The graph of emissivity spectra of coarse quartz resampled to ASTER thermal infrared bands

According to the curve characteristics shown in Figure 3, this paper summarized the correspondence between the residual radiation features of quartz and ASTER thermal infrared bands(seen in table1). As a result, it provides the basis for choosing different band combinations to extract the silicification information.

TABLE 1 THE CORRESPONDENCE TABLE BETWEEN RESIDUAL RADIATION VALUE OF COARSE QUARTZ AND ASTER THERMAL INFRARED BANDS

\begin{tabular}{|l|c|l|l|l|c|}
\hline \multicolumn{1}{|c|}{ Mineral } & \multicolumn{5}{|c|}{ ASTER Thermal Infrared Bands } \\
\hline $\begin{array}{l}\text { Quartz } \\
\text { emissivity }\end{array}$ & Band 10 & Band 11 & Band 12 & Band 13 & Band 14 \\
\cline { 2 - 6 } & medium & high & low & high & high \\
\hline
\end{tabular}

B. Silicification information extraction based on the decorrelation stretch and color composite

Soha and Schwartz proposed the method of decorrelation stretch in 1978, Gines Pie et al. gradually improved and developed this method later. It is used to enhance the contrast of multi-band image, its mathematical meaning is inverse transformation of multi-dimensional orthogonal linear transformation on the basis of statistical features ${ }^{[5]}$. The specific process of decorrelation stretch is actually to process the thermal infrared data by forward principal component transformation, contrast stretching and the reverse principal component transformation. It integrates advantages of the principal component transform and contrast stretching, and eliminates high correlation of multi-spectral data in order to generate a beautiful and pastel color image.

The thermal infrared image of ASTER reflects the surface temperature and emissivity, and the temperature information is main information. There is high correlation in the thermal infrared bands of ASTER, because the surface temperature is usually under 39 degree Celsius. Futhermore, it is not conducive to extract the geological thematic information. The method of decorrelation stretch extends the low correlation information in the original image selectively, and improves the image saturation. This method enhances the emissivity information, and suppresses the temperature information of surface features, essentially. As a result, it improves the effect of geological interpretation and application analysis. The paper extracted the quartz information by decorrelation stretch and color composite with band13, band12,band11 of ASTER based on the diagnostic spectral features of quartz. And then, the image was processed by linear stretch and median filtering, the final result is shown in figure 4 .



Fig.4.The graph of quartz information extraction based on the decorrelation stretch and color composite with band13, band 12,band 11 of ASTER

The color from blue - green - orange - purple - red represents the change of quartz content from low to high from Fig4, the river and its sides in the image shows the color of purple- red, it represents the high quartz content, because it has shallow depth, and there are a large number of silicon-rich rocks in the watercourse. But it doesn't indicate the river is silicification information associated with uranium mineralization. The paper sighed the silicification area with red circle marked with letter A to $\mathrm{H}$,excluded the obvious interference information,

\section{Silicification information extraction based on the quantitative inversion of $\mathrm{SiO}_{2}$ content}

Since the sensor of ASTER has been put into use, many scholars have done some qualitative or quantitative research about using ASTER thermal infrared data to inverse the content of $\mathrm{SiO}_{2}$. Ninomiya ${ }^{[7]}$ used simulation data of ASTER to inverse the content of $\mathrm{SiO}_{2}$ quantitatively by method of artificial neural network. Chen Jiang ${ }^{[8]}$ resampled spectra of minerals from ASU spectral library to ASTER thermal infrared bands and made bands ratio process with mineral spectra, analyzed the correlation between bands ratio and $\mathrm{SiO}_{2}$ content, and then chose maximum correlation coefficient to do the logarithmic simulation. At last, he gained the numerical relationship between emissivity spectra and $\mathrm{SiO}_{2}$ content. The formula of $\mathrm{SiO}_{2}$ content quantitative inversion is as follows: $\mathrm{SiO}_{2} \%=28.9 \times \log (6.6 \times$ band $13 \times$ band $14 /($ band $10 \times$ band 12$))(2)$ 
Above all, most methods of $\mathrm{SiO}_{2}$ content retrieval used mineral emissivity and the corresponding $\mathrm{SiO}_{2}$ content to do the statistical analysis and got the inversion formula. Chen Jiang has done this work in detail, but its practical application is limited to distinguish acid and alkali lithology and doesn't expend its application to combine with the actual prospecting. Based on the emissivity separated from ASTER thermal infrared data and formula $2^{[9]}$, the paper completed the quantitative inversion of surface $\mathrm{SiO}_{2}$ content in TAOSHAN uranium deposits programming in ENVI / IDL, and extracted the silicified fault zone, granite-body and red layer information associated with uranium mineralization according to the relative value of $\mathrm{SiO}_{2}$ content(Fig5). Futhermore, the information is consistent with the geological map.

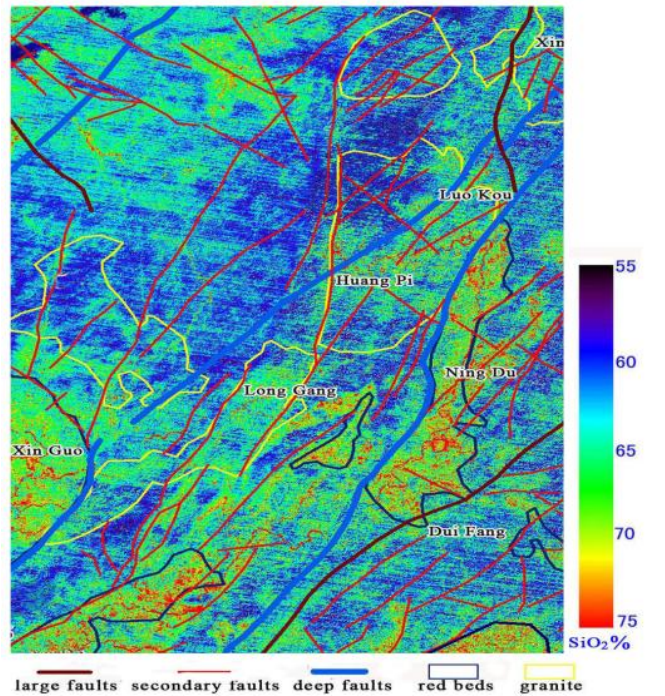

Fig.5.The overlay map of $\mathrm{SiO}_{2}$ content and geological information

\section{ALTERATION INFORMATION VERIFICATION}

The paper chose the important abnormal area to verify in the field based on the silicification information extraction, and discovered a new and large fault zone. The strong silicification is developed in the fault and the silicified zone is long(Fig6). Spectroscopy measurement was done in the silicified zone, the content of uranium is up to $220 \mathrm{ppm}$,it belongs to the high mineralized anomalies. Therefore, the practice proves that the silicification information extracted in this paper has achieved good results in the study area.

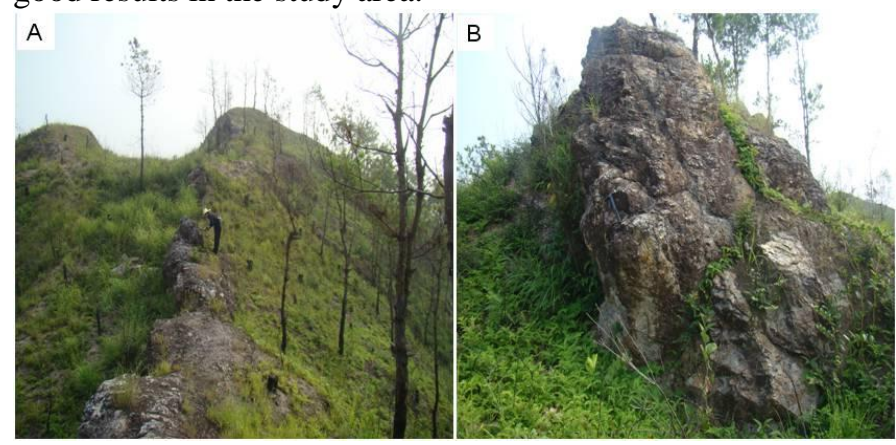

Fig.6.A : Outlook map of silicified fault zone;B:close map of silicified fault zone

\section{CONCLUSION}

The spatial resolution of ASTER thermal infrared bands is 90 meters, and there are five bands in multi-spectral thermal infrared bands. The paper could not extract the mineral species and small-scale silicification information precisely because of the restriction of spatial and spectral resolution. Besides, the paper does not eliminate the impact of soil and vegetation in the inversion formula simulation of $\mathrm{SiO}_{2}$ content, and hence the inversion result of $\mathrm{SiO}_{2}$ content is a little lower than actual value.

Despite the existence of many uncertainties, the silicification information extracted in the paper highlights the large silicified fault zones, granite-rock and red beds with high $\mathrm{SiO}_{2}$ content, and the paper achieved the purpose of extracting uranium mineralization factors. The important information above could be used for extracting and analyzing the metallogenic essential factors of granite-type uranium deposits. What's more, the results will provide important clues to choose prospective area in uranium deposits.

\section{ACKNOWLEDGMENT}

Thank for the help of De-Chang Liu in the Beijing Research institute of Uranium Geology, National Key Laboratory of Remote Sensing Information and Image Analysis Technology.

\section{REFERENCES}

[1] Jielin Zhang. Hyperspectral information identification for characterizing metallogenic factors of Taoshan uranium ore field[J].World Nuclear Geoscience,2007,24(4),pp. 216-217

[2] Letian Du, “Granite-type uranium corpus,"Atomic Energy Press, Beijing in China,pp. 29,1982

[3] Jinbai Huang, "Chinese Uranium Mineralization Introduction,"Aerial Survey Publishers, Shi Jiazhang in Beijing,pp.11,2005

[4] Y.Yamaguchi,H.Fujisada.ASTER Instrument Characterization andOperationScenario[J].AdvancesinSpace Research,1999, VOl.23(8),pp.1415-1424

[5] Yingshi Zhao, "The principles and methods of remote sensing application and analysis,"Scientific Publishers,Bei jin in China,pp.110-115,2002

[6] Johnson,B.R. "IN-Scene Atmospheric Compensation:Application to SEBASS Data Collected at the ARM Site",Technical Report,Space and Encironment Technology Center,the Aerospace Corporation,pp.122-125,May 1998.

[7] Ninomiya $\mathrm{Y}$. "Quantitative estimation of $\mathrm{SiO} 2$ content in igneous rocks using thermal infrared spectral with a neural net work approach",IEEE Transactions on Geoscience and Remote Sensing, 1995,Vol. 33(3),pp.684-691

[8] Chen Jiang,Wang Anjian. "The Pilot Study on Petrochemistry Components Mapping with ASTER Thermal Infrared Remote Sensing Data", Journal of Remote Sensing,2007,Vol.11(4),pp. 601-602

[9] Wang Jun-hu. " $\mathrm{SiO}_{2}$ Content Retrieving and Metallogenic Factors Identification of Granite-Type Uranium ore-field Based on Thermal Infrared Data”. Geo-Information Science, 2010,VOL12(1),pp.126-132 